\title{
Magnetic resonance-guided, high-intensity focused ultrasound sonolysis: potential applications for stroke
}

\author{
Adeel llyas, MD, ${ }^{1}$ Ching-Jen Chen, MD, ${ }^{2}$ Dale Ding, MD, ${ }^{3}$ Andrew Romeo, MD, ${ }^{1}$ \\ Thomas J. Buell, MD, ${ }^{2}$ Tony R. Wang, MD, ${ }^{2}$ M. Yashar S. Kalani, MD, PhD, ${ }^{2}$ and Min S. Park, MD ${ }^{2}$ \\ 'Department of Neurosurgery, University of Alabama at Birmingham, Alabama; ${ }^{2}$ Department of Neurological Surgery, University \\ of Virginia Health System, Charlottesville, Virginia; and ${ }^{3}$ Department of Neurosurgery, Barrow Neurological Institute, Phoenix, \\ Arizona
}

\begin{abstract}
Stroke is one of the leading causes of death worldwide and a significant source of long-term morbidity. Unfortunately, a substantial number of stroke patients either are ineligible or do not significantly benefit from contemporary medical and interventional therapies. To address this void, investigators recently made technological advances to render transcranial MR-guided, high-intensity focused ultrasound (MRg-HIFU) sonolysis a potential therapeutic option for both acute ischemic stroke (AIS) - as an alternative for patients with emergent large-vessel occlusion (ELVO) who are ineligible for endovascular mechanical thrombectomy (EMT) or as salvage therapy for patients in whom EMT fails-and intracerebral hemorrhage $(\mathrm{ICH})$ - as a neoadjuvant means of clot lysis prior to surgical evacuation. Herein, the authors review the technological principles behind MRg-HIFU sonolysis, its results in in vitro and in vivo stroke models, and its potential clinical applications. As a noninvasive transcranial technique that affords rapid clot lysis, MRg-HIFU thrombolysis may develop into a therapeutic option for patients with AIS or ICH. However, additional studies of transcranial MRg-HIFU are necessary to ascertain the merit of this treatment approach for thrombolysis in both AIS and ICH, as well as its technical limitations and risks.
\end{abstract}

https://thejns.org/doi/abs/10.3171/2017.11.FOCUS17608

KEY WORDS focused ultrasound; stroke; sonolysis; hemorrhagic; technology

$\mathrm{T}$ $\mathrm{HE}$ incidence of ischemic and hemorrhagic stroke worldwide is $110-130$ and $55-60$ cases per 100,000 people, respectively. ${ }^{21}$ In the United States, stroke is the fifth leading cause of death and a significant source of morbidity. ${ }^{27,53}$ Although intravenous tissue plasminogen activator (IV-tPA) remains the standard of care in eligible patients with acute ischemic stroke (AIS), concurrent endovascular mechanical thrombectomy (EMT) with latestgeneration devices is recommended in select patients with emergent large-vessel occlusions (ELVOs) ${ }^{36,60,70}$ Unfortunately, fewer than $10 \%$ and $15 \%$ of patients with AIS are eligible for IV-tPA and EMT, respectively. ${ }^{12,64}$ With respect to intracerebral hemorrhage (ICH), clot evacuation and decompressive craniectomy appear to decrease death in select patients but have not been proven to reduce morbidity. ${ }^{18,26}$ Therefore, a substantial number of patients with stroke either are ineligible or do not significantly benefit from current optimal medical and surgical treatment. To address this void, investigators recently made technological advances to render transcranial sonolysis a potential therapeutic option for both AIS - as an alternative for patients with ELVO who are ineligible for EMT or as salvage therapy for patients in whom EMT fails - and ICH - as a neoadjuvant means of clot lysis prior to evacuation. ${ }^{10,46,51,71}$

The term "sonothrombolysis" refers to ultrasound-mediated thrombolysis with the concurrent use of adjuvant therapy (for example, tPA, microbubbles); on the other hand, the term "sonolysis" is used when no concurrent adjuvant therapy is employed to achieve clot lysis. ${ }^{63}$ Although the concept of sonolysis was first proposed by Anschuetz and Bernard in the 1960s, it was not until the introduction of transcranial Doppler ultrasonography (TCD-US) in the 1980s that technological advances permitted the applica-

ABBREVIATIONS AIS = acute ischemic stroke; DSA = digital subtraction angiography; ELVO = emergent large-vessel occlusion; EMT = endovascular mechanical thrombectomy; ICH = intracerebral hemorrhage; IV-tPA = intravenous tissue plasminogen activator; MCA = middle cerebral artery; MRg-HIFU = MR-guided, high-intensity focused ultrasound.

SUBMITTED September 28, 2017. ACCEPTED November 21, 2017.

INCLUDE WHEN CITING DOI: 10.3171/2017.11.FOCUS17608. 
tion of ultrasound in an intracranial setting. ${ }^{1,5,42,47}$ In so doing, novel applications for the treatment of stroke were realized. Following in vitro and in vivo studies in the 1990s, the initial clinical application of low-intensity ultrasoundenhanced sonothrombolysis was reported by Alexandrov et al., who observed better and faster recanalization in AIS patients treated with IV-tPA who underwent concurrent TCD-US. 3,722,42,55 Subsequent randomized clinical trials offered encouraging results for low-intensity, highfrequency $(>300 \mathrm{kHz})$ ultrasound-enhanced sonothrombolysis. $4,16,20,49,54,69$

Magnetic resonance-guided, high-intensity focused ultrasound (MRg-HIFU) sonolysis offers several advantages over ultrasound-enhanced sonothrombolysis, which is merely an application of diagnostic ultrasonography and therefore requires IV-tPA administration and is easily attenuated by thicker regions of the calvaria. In addition, ultrasound-enhanced thrombolysis is operator dependent, and its therapeutic effect is achieved on the order of hours after continuous application. Hence, this technique is only applicable in approximately $2 \%-27 \%$ of AIS patients treated with IV-tPA and achieves complete recanalization rates of 27\%-78\%., , $19,20,28,37,49,56$ Furthermore, given its negligible thermal effects and the stagnancy of the clot, lowintensity sonothrombolysis is not applicable to ICH., ${ }^{1,2,9,68}$ In contrast, MRg-HIFU thrombolysis is an emerging stand-alone therapy for rapid transcranial clot disintegration in patients with ELVO and ICH and, according to in vitro and in vivo models, can potentially achieve recanalization and liquefaction rates of $63 \%-93 \%$ and $>95 \%$, respectively. $10,25,30,45,50,51,73,75$ Herein, we review the technological development, preclinical results, and future applications of MRg-HIFU thrombolysis.

\section{Technology and Techniques}

Magnetic resonance-guided HIFU thrombolysis relies on the piezoelectric effect to generate acoustic waves, which travel transcranially and focally transmit energy to the clot, resulting in lysis via cavitation.$^{59}$ The power output of HIFU is typically on the order of $10^{2}-10^{4} \mathrm{~W} / \mathrm{cm}^{2}$, and several technological advances have enabled safe and efficient delivery of this power. Hemispheric, large-aperture, multielement phased-array transducers minimize focal skull attenuation by spreading acoustic energy across a wide region of the calvaria. ${ }^{23,32,33,67}$ A continuously chilled degassed-water interface between the transducers and the patient's shaved, clean scalp not only decreases scalp heating but also improves acoustic wave coupling. ${ }^{23,67}$ Phase correction terms are necessary to maintain target phase alignment and improve HIFU efficiency in the setting of the heterogeneous bony architecture of the calvaria and are computed for each individual transducer based on a prior CT scan of the head. ${ }^{13,14,23,38,67}$ Thermal MRI monitoring is critical in preventing untoward thermal ablation of tissue since the various parameter estimates for each transducer cannot precisely anticipate individual patient scalp, skull, and intracranial tissue idiosyncrasies. ${ }^{23,35,67}$

Inertial acoustic cavitation is the primary mechanism by which MRg-HIFU thrombolysis achieves clot disintegration. $6,11,33,45,57,71,73$ Acoustic waves impart momentum to the fluid immediately surrounding the clot, creating microbubbles. ${ }^{45,73}$ These microbubbles rapidly collapse along the clot surface, emitting shock waves and liquid jet speeds of more than $1 \mathrm{~km} / \mathrm{sec}$, which promote thrombolysis. ${ }^{9,31,71}$ The optimal frequency to effectively induce localized inertial cavitation while minimizing surrounding tissue injury depends on several factors. High frequency (usually on the order of $\mathrm{MHz}$ ) is necessary to produce a sufficiently focused ultrasound beam. However, high-frequency ultrasound is more rapidly attenuated by the calvaria. ${ }^{23,72}$ Calvarial attenuation is less of a concern with low-frequency ultrasound, which generates more robust cavitation. However, low-frequency waves can be difficult to focus, resulting in thermal and mechanical damage to adjacent tissues. . $, 23,58,68,72$

Several techniques have been developed to improve the safety and efficiency of MRg-HIFU thrombolysis. The presence of intracranial standing waves secondary to resonance from acoustic reflections within the cranial vault can have unpredictable and detrimental effects, including the formation of unexpected hot spots and an elevated risk of ICH. ${ }^{8,16,67}$ One method of decreasing the likelihood of standing-wave formation is to sharpen the focal volume by increasing the emission frequency. ${ }^{15,67}$ Additionally, given that standing waves are more likely to accumulate during extended ultrasound exposure, pulsed sonication can reduce the risk that is associated with resonance. ${ }^{6,10,67}$ Pulsed sonication has also been found to yield superior ELVO recanalization rates in preclinical studies.6,62,73 Another method to mitigate standing-wave formation is via multifrequency sonication. ${ }^{40,41}$ Not only does multifrequency HIFU decrease resonance, but it also allows for simultaneous multiregional cavitation, which improves selectivity of the focal point to cavitation, and permits cavitation mapping. ${ }^{17,66}$

\section{In Vitro Studies}

Several in vitro models have demonstrated the effectiveness of appropriately selected HIFU parameters for thrombolysis (Table 1). Westermark et al. showed that marked thrombolysis of clots in a degassed water-filled bowl could be achieved using an acoustic focus from a 1.1-MHz HIFU transducer with a pulsed sequence for 30 seconds, compared with the use of 30 shock waves or continuous HIFU. ${ }^{72}$ Rosenschein et al. were able to achieve a thrombolysis rate of $91 \%$ at optimum pulsedHIFU parameters $(1.5 \mathrm{MHz}, 1: 25$ duty cycle, 200- $\mu \mathrm{sec}$ pulse length) and showed that arterial damage ensues following prolonged exposure to HIFU $\left(45 \mathrm{~W} / \mathrm{cm}^{2}\right.$ for $\geq$ 5 minutes). ${ }^{62}$ Maxwell et al. investigated the relationship between HIFU intensity and thrombolysis rate using a 1-MHz pulsed-HIFU transducer. ${ }^{45}$ Complete fractionation was achieved at peak pulse mean intensities of $\geq 3600 \mathrm{~W} /$ $\mathrm{cm}^{2}$ (corresponding to $\geq 8$-MPa peak negative pressures) within 5 minutes of treatment. The aforementioned studies also measured debris size following lysis and showed that at least $93 \%$ of debris particles were subcapillary in caliber $\left(<8 \mu \mathrm{m}\right.$ in diameter). ${ }^{45,62}$ Wright et al. varied pulse length and acoustic power while keeping total imparted energy constant in a $1.51-\mathrm{MHz}$ pulsed-HIFU in vitro clot 
TABLE 1. Summary of studies using in vitro and in vivo models to determine the safety and feasibility of HIFU for thrombolysis

\begin{tabular}{|c|c|c|c|}
\hline $\begin{array}{l}\text { Authors } \\
\& \text { Year }\end{array}$ & Transcranial & Methods & Results \\
\hline $\begin{array}{l}\text { Pajek et al., } \\
2014\end{array}$ & Yes & $\begin{array}{l}\text { 1) In vitro model: rabbit clots suspended in artificial flow } \\
\text { system w/ injected microbubbles; } 2 \text { ) in vivo: rabbit ELVO } \\
\text { model: } 2 \times 2 \times 2-\text { mm clots inserted into It ICA, resulting } \\
\text { in proximal MCA infarction } \\
\text { Parameters: } 1.51 \mathrm{MHz} \text {, varied acoustic power (19-137 W), } \\
\quad \text { varied pulse length ( } 0.1 \text { or } 1 \mathrm{msec}), 2 \text {-sec duration }\end{array}$ & $\begin{array}{l}\text { 1) Mean threshold intensity to achieve inertial cavitation } \\
\text { was } 49 \pm 9 \mathrm{~W} ; 2 \text { ) overall recanalization rate } 71 \%\end{array}$ \\
\hline $\begin{array}{l}\text { Hölscher et } \\
\text { al., } 2013\end{array}$ & Yes & $\begin{array}{l}\text { 1) In vitro model: human clot suspended in ex vivo human } \\
\text { calvaria in a hemispheric, degassed-water transducer; } \\
\text { 2) in vivo: rabbit ICA ELVO model } \\
\text { Parameters: } 220 \mathrm{kHz} \text {, varied acoustic power ( } 100-400 \mathrm{~W}) \text {, } \\
\text { varied pulse width }(0.1-200 \text { msec), varied duty cycle } \\
(5 \%-50 \%), 30 \text {-sec duration }\end{array}$ & $\begin{array}{l}\text { 1) Thrombolysis rates ranged from } 10 \% \text { to } 42 \%,>400 \\
\text { W acoustic output needed to achieve clot fragmenta- } \\
\text { tion, higher duty cycles \& longer pulse width yielded } \\
\text { increased thrombolysis rates; 2) } 10 \% \text { recanalization rate, } \\
\text { primarily a feasibility study }\end{array}$ \\
\hline $\begin{array}{r}\text { Burgess et } \\
\text { al., } 2012\end{array}$ & Yes & $\begin{array}{l}\text { In vivo model: rabbit ELVO model: } 2 \times 2 \times 2-\mathrm{mm} \text { clots } \\
\text { inserted into It ICA, resulting in proximal MCA infarction } \\
\text { Parameters: } 1.5 \mathrm{MHz} \text {, varied acoustic power }(275-550 \mathrm{~W}) \text {, } \\
\text { 1-msec burst of } 1-\mathrm{Hz} \text { pulse frequency, } 20 \text {-sec exposure }\end{array}$ & $\begin{array}{l}\text { Recanalization rates in the } 275-, 415-\text {, and } 550 \text {-W groups } \\
\text { were } 0 \%(0 / 4), 50 \%(2 / 4) \text {, and } 71 \%(5 / 7) \text {, respectively; } \\
\text { basal brain surface bleeding in } 25 \%(1 / 5) \text {, w/o associ- } \\
\text { ated vessel damage; mean time from ischemic confirma- } \\
\text { tion on DSA to recanalization } 59 \text { mins }\end{array}$ \\
\hline $\begin{array}{l}\text { Wright et al., } \\
\quad 2012\end{array}$ & No & $\begin{array}{l}\text { 1) In vitro model: rabbit clots suspended in degassed-water } \\
\text { tank; } 2) \text { in vivo: } 1-\mathrm{cm} \text { rabbit femoral artery occlusion } \\
\text { Parameters: } 1.51 \mathrm{MHz} \text {, varied acoustic power ( } 120-300 \\
\text { W), varied pulse lengths }(0.1-1 \mathrm{msec}), 0.1 \% \text { duty cycle }\end{array}$ & $\begin{array}{l}\text { 1) Clot erosion vol increased w/ power \& pulse length, in- } \\
\text { creased pulse length associated w/ reduced pulse size; } \\
\text { 2) } 1 \text {-msec pulse length at } 300 \mathrm{~W} \text { achieved partial resto- } \\
\text { ration in } 63 \%(5 / 8) \text { femoral arteries, w/ } 1 \text { minor bleed }\end{array}$ \\
\hline $\begin{array}{r}\text { Maxwell et } \\
\text { al., } 2011\end{array}$ & No & $\begin{array}{l}\text { In vivo model: } 2-\mathrm{cm} \text { thrombus in pig femoral veins } \\
\text { Parameters: } 1 \mathrm{MHz} \text {, varied average peak negative pres- } \\
\text { sure }\left(49-105 \mathrm{~W} / \mathrm{cm}^{2}\right), 5 \text { cycle bursts at } 1-\mathrm{kHz} \text { pulse } \\
\text { frequency }\end{array}$ & $\begin{array}{l}58 \%(7 / 12) \text { cases showed improved flow; } 75 \%(3 / 4) \text { femoral } \\
\text { veins showed minor zones of hemorrhage }\end{array}$ \\
\hline $\begin{array}{l}\text { Maxwell et } \\
\text { al., } 2009\end{array}$ & No & $\begin{array}{l}\text { In vitro model: } 4 \times 20 \text {-mm cylindrical canine clots placed in } \\
\text { tube, suspended in degassed-water tank } \\
\text { Parameters: } 1 \mathrm{MHz} \text {, varied peak average intensities (150- } \\
\left.7000 \mathrm{~W} / \mathrm{cm}^{2}\right), 5 \text { cycle bursts at } 1-\mathrm{kHz} \text { pulse frequency }\end{array}$ & $\begin{array}{l}\text { At } \geq 3600 \mathrm{~W} / \mathrm{cm}^{2} \text {, significantly increased thrombolysis rate } \\
\text { observed; clots completely lysed in } 1.5-5 \mathrm{~min} ;>96 \% \text { of } \\
\text { clot debris }<5 \mu \mathrm{m} \text { in diameter }\end{array}$ \\
\hline $\begin{array}{l}\text { Rosenschein } \\
\text { et al., } \\
2000\end{array}$ & No & $\begin{array}{l}\text { In vitro model: bovine ICA segments w/ intraluminal bovine } \\
\text { clots immersed in tank w/ degassed water } \\
\text { Parameters: } 1) \text { focal spot average intensity } 40 \mathrm{~W} / \mathrm{cm}^{2} \text {, } \\
\text { varied pulse length ( } 50-400 \mu \mathrm{sec}) \text {, varied duty cycles } \\
\quad(1: 10-1: 40), 4-\text { min exposure; } 2 \text { ) varied average intensity } \\
\left(10-55 \mathrm{~W} / \mathrm{cm}^{2}\right), 200-\mu \mathrm{sec} \text { pulse length, } 1: 25 \text { duty cycle }\end{array}$ & $\begin{array}{l}\text { 1) Optimal pulse length \& duty cycles were } 200 \mu \text { sec \& } \\
1: 25 \text {, respectively, to yield } 90 \% \pm 1 \% \text { thrombolysis } \\
\text { efficiency; } 2 \text { ) no sonographic evidence of clot at optimal } \\
40-W / \mathrm{cm}^{2} \text { intensity, } 93 \% \pm 1 \% \text { of clots became subcapil- } \\
\text { lary }(<8 \mu \mathrm{m}) \text { in size, histological analysis showed mild } \\
\text { tissue damage } w / \geq 5 \text { mins exposure }\end{array}$ \\
\hline $\begin{array}{l}\text { Westermark } \\
\text { et al., } \\
1999\end{array}$ & No & $\begin{array}{l}\text { In vitro model: } 5 \text {-mm-thick human clot suspended in bowl } \\
\text { w/ degassed water } \\
\text { Parameters: 1) } 1.1 \mathrm{MHz} \text {, } 16 \text {-element array, continuous } \\
\text { emission, } 30 \text {-sec exposure; 2) } 1.1 \mathrm{MHz}, 30-\mathrm{W} \text { average } \\
\text { output, } 16 \text {-element array, pulsed emission at } 67 \mathrm{~Hz} \text { w/ } \\
\text { 38-msec pause time, } 30 \text {-sec exposure }\end{array}$ & $\begin{array}{l}\text { 1) } 11 \% \pm 6 \% \text { clot weight reduction; 2) } 99 \% \pm 2 \% \text { clot weight } \\
\text { reduction }\end{array}$ \\
\hline
\end{tabular}

ICA = internal carotid artery.

model and demonstrated a direct relationship between these 2 parameters and clot erosion. ${ }^{73}$ In a transcranial in vitro model using human clots suspended in ex vivo human calvariae, Hölscher et al. attained thrombolysis rates of $10 \%-42 \%$ and found that $>400 \mathrm{~W}$ of acoustic output was needed to achieve clot fragmentation. ${ }^{29}$

\section{In Vivo Studies}

In vivo studies that have assessed the feasibility of HIFU thrombolysis are scarce (Table 1). Maxwell et al. developed a porcine thrombus model using 2 balloon cath- eters inflated to trap a 20-mm segment of the femoral vein, into which thrombin was infused. ${ }^{46}$ Ultrasound-guided pulsed HIFU was performed using a $1-\mathrm{MHz}$ transducer to generate peak pulse mean intensities of 9800-21,000 $\mathrm{W} / \mathrm{cm}^{2}$ (corresponding to peak negative pressures of 14 $19 \mathrm{MPa}$ ). A total of 12 cases were assessed, 10 (83\%) of which demonstrated signs of luminal cavitation. Of these 10 cases, 7 showed Doppler ultrasonographic evidence of improved flow. Assessment of vessel damage in the 12 HIFU-treated cases was confounded by injury due to catheter insertion and balloon dilation. Wright et al. used 
TABLE 2. List of studies using in vitro and in vivo models to determine safety and feasibility of HIFU for ICH

\begin{tabular}{|c|c|c|c|}
\hline Authors \& Year & Transcranial & Methods & Results \\
\hline $\begin{array}{l}\text { Harnof et al., } \\
2014\end{array}$ & Yes & $\begin{array}{l}\text { 1) In vitro model: } 300 \text {-ml clot introduced in ex vivo human skull; } 2 \text { ) } \\
\text { in vivo: porcine lobar ICH model; } 3 \text { ) in vivo: in vivo porcine } 3-\mathrm{ml} \\
\text { ICH model implanted w/in ex vivo human skull } \\
\text { Parameters: } 230 \mathrm{kHz} \text {, varied acoustic power ( } 600-900 \mathrm{~W} \text { ), pulsed } \\
\text { sonication, } 10 \% \text { duty cycle, } 5 \text { - to } 10 \text {-sec duration }\end{array}$ & $\begin{array}{l}\text { 1) } 50 \%(9 / 18) \text { sonications resulted in liquefac- } \\
\text { tion w/o thermal effect; } 2 \& 3) \text { clot liquefaction } \\
\text { achieved w/ modest increase in surrounding } \\
\text { tissue temperature }\end{array}$ \\
\hline $\begin{array}{l}\text { Monteith et al., } \\
2013\end{array}$ & Yes & $\begin{array}{l}\text { 1) In vitro model: human clots placed in wells suspended in ex vivo } \\
\text { human calvaria; } 2 \text { ) in vivo: swine ICH model; } 3 \text { ) in vitro: ex vivo } \\
\text { human ICH model w/ implanted } 40 \text {-ml human blood clots } \\
\text { Parameters: } 230 \mathrm{kHz} \text {, varied acoustic power ( } 750-3950 \mathrm{~W}) \text {, } \\
\text { varied pulse width around } 100 \mu \mathrm{sec} \text {, varied duty cycle around } \\
10 \%, 30 \text {-sec duration }\end{array}$ & $\begin{array}{l}\text { 1) Optimal thrombolysis parameters were } 3950 \\
\text { W, } 1-\mathrm{kHz} \text { pulse repetition rate, } 10 \% \text { duty cycle, } \\
\text { duration of } 30 \mathrm{sec} \text {, average vol of } 3.6 \mathrm{ml} \text { lysed; } \\
\text { 2) complete lysis of } 4-\mathrm{ml} \mathrm{ICH} \text { w/o additional } \\
\text { brain injury performed; } 3 \text { ) >95\% liquefaction } \\
\text { rate permitting minimally invasive aspiration }\end{array}$ \\
\hline
\end{tabular}

a rabbit femoral artery clot model with vascular clamps to occlude a $1-\mathrm{cm}$ segment. ${ }^{73}$ Pulsed HIFU was performed with a $1.51-\mathrm{MHz}$ transducer to generate acoustic powers of 185,215 , and $300 \mathrm{~W}$ using 1-msec pulses. Partial flow restoration rates were $0 \%(0 / 5), 50 \%(1 / 2)$, and $63 \%(5 / 8)$ at these settings, respectively. However, none of these cases demonstrated complete flow restoration. One minor bleed (1-2 drops) that occurred in the 300-W group resolved within 2 minutes. These studies demonstrated the feasibility of extracranial thrombolysis using HIFU.

Burgess, Pajek, and colleagues performed in vivo studies of intracranial ELVO thrombolysis using MRgHIFU. ${ }^{10,57}$ In the first of these 2 studies, a model of embolic stroke was developed by injecting $8-\mathrm{mm}^{3}$ rabbit blood clots, prepared and assessed in vitro, into the left internal carotid artery of anesthetized rabbits and confirming middle cerebral artery (MCA) occlusion via digital subtraction angiography (DSA). Magnetic resonance imaging localization of the clot was performed using fast gradient-echo and time-of-flight sequences. Pulsed HIFU was performed using a 1.51-MHz transducer to generate acoustic energies of $275-550 \mathrm{~W}$ in $1-\mathrm{msec}$ bursts with a $1-\mathrm{Hz}$ pulse repetition frequency. Sonication proceeded from distal to proximal in $0.75-\mathrm{mm}$ increments. Recanalization was assessed using DSA. Respective recanalization rates in the 275-, 415-, and $550-\mathrm{W}$ groups were $0 \%$ (0/4 animals), $50 \%$ (2/4), and $71 \%$ $(5 / 7)$. Histological examination revealed intact and undamaged arteries and arterioles. In 1 of the latter 5 cases, there was evidence of bleeding from the base of the brain, without associated vessel damage. Small regions of Prussian blue staining were observed in distal cortical regions, indicating that most debris cleared the proximal cerebral vasculature. The mean time from confirmation of the clot via DSA to recanalization was 59 minutes. In the second study by this same group, intravascular perfluorocarbon droplets were shown to reduce the necessary HIFU intensity output required to achieve MCA clot thrombolysis by $76 \%$ in a similar rabbit model of AIS. The recanalization rates were $71 \%$ in the group receiving 1-msec pulse durations. These studies demonstrated the feasibility of transcranial MRgHIFU thrombolysis for AIS.

Two in vivo studies have demonstrated the feasibility of transcranial MRg-HIFU in ICH sonolysis (Table 2). ${ }^{25,50}$ Monteith et al. determined optimal HIFU parameters in an in vitro model in which human clots were suspended within ex vivo human calvaria and lysed with a pulsed $230-\mathrm{kHz}$ transducer. ${ }^{50}$ Optimal parameters of $3950 \mathrm{~W}$ of acoustic output, a pulse repetition rate of $1 \mathrm{kHz}$, and a $10 \%$ duty cycle yielded complete lysis of 3.6-ml clots on average. Subsequently, these optimal parameters were applied to both an in vitro ICH model in which a 40-ml clot was implanted in an ex vivo human brain and an in vivo swine ICH model and demonstrated a $>95 \%$ liquefaction rate permitting minimally invasive clot aspiration and complete lysis of 4-ml clots without additional brain injury, respectively. Harnof et al. used a pulsed, 230-kHz transducer with $700 \mathrm{~W}$ of acoustic output, a $10 \%$ duty cycle, and a 5-second duration to achieve complete liquefaction in a model of porcine ICH implanted in a cadaveric human calvaria. ${ }^{25}$ Minimal, nondamaging thermal effects were observed in surrounding brain regions.

\section{Potential Applications}

Transcranial MRg-HIFU thrombolysis is an emerging technology that has the potential to be a valuable addition to the AIS and ICH treatment armamentarium. Regarding AIS treatment, MRg-HIFU sonolysis offers several advantages over sonothrombolysis. Given that IV-tPA alone can require several hours to achieve recanalization, MRg-HIFU could be performed concurrently to achieve more rapid thrombolysis and superior recanalization rates. Additionally, the application of MRg-HIFU as a sole treatment modality would circumvent tPA administration and associated complications. ${ }^{74}$ Furthermore, MRg targeted therapy not only limits untoward thermal effects of HIFU but also decreases operator dependence. Compared with EMT, MRg-HIFU may offer a completely noninvasive therapy for AIS secondary to ELVO. However, the potential benefits of this therapy must be weighed against the risks of unintended thermal damage to brain parenchyma due to heating of the skull base (that is, during treatment of proximal occlusions) or calvaria (that is, during treatment of distal occlusions). Compared with EMT, MRg-HIFU thrombolysis may yield superior disintegration rates in cerebral venous sinus thrombosis since these clots are typically larger in caliber; however, current application may be limited to deep-seated thromboses. ${ }^{34,44,65}$ 
Regarding ICH treatment, the current standard of care includes correction of underlying coagulopathies, optimization of blood pressure and serum glucose, anticonvulsant therapy for new-onset seizures, and CSF diversion in patients with hydrocephalus. ${ }^{26}$ The role of surgical intervention for ICH continues to evolve. The results of recent randomized trials suggest that catheter-based hematoma evacuation may be advantageous in select patients. ${ }^{24,48,52}$ However, an important consideration in this approach is catheter alignment along the long axis of the clot, which can be challenging without compromising critical structures. ${ }^{51}$ Alternatively, MRg-HIFU sonolysis is not only noninvasive but also selectively targets clots of any shape, located in any deep brain region. Thus, MRg-HIFU sonolysis may be a particularly effective therapy for patients with intraventricular hemorrhage for whom surgical clot evacuation is not beneficial. ${ }^{24}$ One drawback of MRg-HIFU is its inability to lyse clots within $2 \mathrm{~cm}$ of the calvaria because of bony attenuation and heat generation; however, these superficial clots are more likely to be amenable to surgical evacuation. ${ }^{39,61}$ In addition, technical complexity and time requirements represent limitations to the current application of MRg-HIFU sonolysis in both AIS and ICH. However, we anticipate that these limitations will become obviated with the more widespread use of MRg-HIFU and technological advancements in the future.

\section{Conclusions}

Magnetic resonance-guided HIFU thrombolysis utilizes hemispheric, large-aperture, multielement phased-array transducers to transmit acoustic energy in a pulsed fashion to disintegrate intracranial clots via inertial cavitation. Several preclinical studies have demonstrated the feasibility of this therapy. As a noninvasive transcranial technique that affords rapid clot lysis, MRg-HIFU thrombolysis may develop into a treatment option for AIS or ICH. However, additional studies of transcranial MRg-HIFU are necessary to ascertain the merit of this therapeutic approach for thrombolysis in both AIS and ICH, as well as its technical limitations and risks.

\section{References}

1. Aaslid R, Markwalder TM, Nornes H: Noninvasive transcranial Doppler ultrasound recording of flow velocity in basal cerebral arteries. J Neurosurg 57:769-774, 1982

2. Ahadi G, Welch CS, Grimm MJ, Fisher DJ, Zadicario E, Ernström K, et al: Transcranial sonothrombolysis using highintensity focused ultrasound: impact of increasing output power on clot fragmentation. J Ther Ultrasound 1:22, 2013

3. Alexandrov AV, Demchuk AM, Felberg RA, Christou I, Barber PA, Burgin WS, et al: High rate of complete recanalization and dramatic clinical recovery during tPA infusion when continuously monitored with $2-\mathrm{MHz}$ transcranial Doppler monitoring. Stroke 31:610-614, 2000

4. Alexandrov AV, Molina CA, Grotta JC, Garami Z, Ford SR, Alvarez-Sabin J, et al: Ultrasound-enhanced systemic thrombolysis for acute ischemic stroke. N Engl J Med 351:2170-2178, 2004

5. Anschuetz R, Bernard HR: Ultrasonic irradiation and atherosclerosis. Surgery 57:549-553, 1965

6. Bader KB, Bouchoux G, Holland CK: Sonothrombolysis. Adv Exp Med Biol 880:339-362, 2016
7. Barnett SB, Ter Haar GR, Ziskin MC, Rott HD, Duck FA, Maeda K: International recommendations and guidelines for the safe use of diagnostic ultrasound in medicine. Ultrasound Med Biol 26:355-366, 2000

8. Baron C, Aubry JF, Tanter M, Meairs S, Fink M: Simulation of intracranial acoustic fields in clinical trials of sonothrombolysis. Ultrasound Med Biol 35:1148-1158, 2009

9. Brujan EA, Nahen K, Schmidt P, Vogel A: Dynamics of laser-induced cavitation bubbles near an elastic boundary. $\mathbf{F}$ Fluid Mech 433:251-281, 2001

10. Burgess A, Huang Y, Waspe AC, Ganguly M, Goertz DE, Hynynen K: High-intensity focused ultrasound (HIFU) for dissolution of clots in a rabbit model of embolic stroke. PLoS One 7:e42311, 2012

11. Chen X, Leeman JE, Wang J, Pacella JJ, Villanueva FS: New insights into mechanisms of sonothrombolysis using ultrahigh-speed imaging. Ultrasound Med Biol 40:258-262, 2014

12. Chia NH, Leyden JM, Newbury J, Jannes J, Kleinig TJ: Determining the number of ischemic strokes potentially eligible for endovascular thrombectomy: a population-based study. Stroke 47:1377-1380, 2016

13. Clement GT, Hynynen K: Correlation of ultrasound phase with physical skull properties. Ultrasound Med Biol 28:617-624, 2002

14. Clement GT, Hynynen K: A non-invasive method for focusing ultrasound through the human skull. Phys Med Biol 47:1219-1236, 2002

15. Clement GT, Sun J, Giesecke T, Hynynen K: A hemisphere array for non-invasive ultrasound brain therapy and surgery. Phys Med Biol 45:3707-3719, 2000

16. Daffertshofer M, Gass A, Ringleb P, Sitzer M, Sliwka U, Els $\mathrm{T}$, et al: Transcranial low-frequency ultrasound-mediated thrombolysis in brain ischemia: increased risk of hemorrhage with combined ultrasound and tissue plasminogen activator: results of a phase II clinical trial. Stroke 36:1441-1446, 2005

17. Deng L, O'Reilly MA, Jones RM, An R, Hynynen K: A multi-frequency sparse hemispherical ultrasound phased array for microbubble-mediated transcranial therapy and simultaneous cavitation mapping. Phys Med Biol 61:84768501,2016

18. Ding D, Przybylowski CJ, Starke RM, Sterling Street R, Tyree AE, Webster Crowley R, et al: A minimally invasive anterior skull base approach for evacuation of a basal ganglia hemorrhage. J Clin Neurosci 22:1816-1819, 2015

19. Eggers J, Koch B, Meyer K, König I, Seidel G: Effect of ultrasound on thrombolysis of middle cerebral artery occlusion. Ann Neurol 53:797-800, 2003

20. Eggers J, König IR, Koch B, Händler G, Seidel G: Sonothrombolysis with transcranial color-coded sonography and recombinant tissue-type plasminogen activator in acute middle cerebral artery main stem occlusion: results from a randomized study. Stroke 39:1470-1475, 2008

21. Feigin VL, Krishnamurthi RV, Parmar P, Norrving B, Mensah GA, Bennett DA, et al: Update on the global burden of ischemic and hemorrhagic stroke in 1990-2013: the GBD 2013 Study. Neuroepidemiology 45:161-176, 2015

22. Francis CW, Onundarson PT, Carstensen EL, Blinc A, Meltzer RS, Schwarz K, et al: Enhancement of fibrinolysis in vitro by ultrasound. J Clin Invest 90:2063-2068, 1992

23. Ghanouni P, Pauly KB, Elias WJ, Henderson J, Sheehan J, Monteith S, et al: Transcranial MRI-guided focused ultrasound: a review of the technologic and neurologic applications. AJR Am J Roentgenol 205:150-159, 2015

24. Hanley DF, Lane K, McBee N, Ziai W, Tuhrim S, Lees KR, et al: Thrombolytic removal of intraventricular haemorrhage in treatment of severe stroke: results of the randomised, multicentre, multiregion, placebo-controlled CLEAR III trial. Lancet 389:603-611, 2017 
25. Harnof S, Zibly Z, Hananel A, Monteith S, Grinfeld J, Schiff $G$, et al: Potential of magnetic resonance-guided focused ultrasound for intracranial hemorrhage: an in vivo feasibility study. J Stroke Cerebrovasc Dis 23:1585-1591, 2014

26. Hemphill JC III, Greenberg SM, Anderson CS, Becker $\mathrm{K}$, Bendok BR, Cushman M, et al: Guidelines for the management of spontaneous intracerebral hemorrhage. A guideline for healthcare professionals from the American Heart Association/American Stroke Association. Stroke 46:2032-2060, 2015

27. Heron M: Deaths: leading causes for 2014. Natl Vital Stat Rep 65:1-96, 2016

28. Hoksbergen AW, Legemate DA, Ubbink DT, Jacobs MJ: Success rate of transcranial color-coded duplex ultrasonography in visualizing the basal cerebral arteries in vascular patients over 60 years of age. Stroke 30:1450-1455, 1999

29. Hölscher T, Ahadi G, Fisher D, Zadicario E, Voie A: MRguided focused ultrasound for acute stroke: a rabbit model. Stroke 44 (6 Suppl 1):S58-S60, 2013

30. Hölscher T, Fisher D, Raman R, Ernstrom K, Zadicario E, Bradley WG, et al: Noninvasive transcranial clot lysis using high intensity focused ultrasound. J Neurol Neurophysiol S1:002, 2011

31. Holzfuss J, Rüggeberg M, Billo A: Shock wave emissions of a sonoluminescing bubble. Phys Rev Lett 81:5434-5437, 1998

32. Hynynen K, Clement GT, McDannold N, Vykhodtseva N, King R, White PJ, et al: 500-element ultrasound phased array system for noninvasive focal surgery of the brain: a preliminary rabbit study with ex vivo human skulls. Magn Reson Med 52:100-107, 2004

33. Hynynen K, Jones RM: Image-guided ultrasound phased arrays are a disruptive technology for non-invasive therapy. Phys Med Biol 61:R206-R248, 2016

34. Ilyas A, Chen CJ, Raper DM, Ding D, Buell T, Mastorakos P, et al: Endovascular mechanical thrombectomy for cerebral venous sinus thrombosis: a systematic review. J Neurointerv Surg 9:1086-1092, 2017

35. Ishihara Y, Calderon A, Watanabe H, Okamoto K, Suzuki $\mathrm{Y}$, Kuroda K, et al: A precise and fast temperature mapping using water proton chemical shift. Magn Reson Med 34:814-823, 1995

36. Jayaraman MV, Hussain MS, Abruzzo T, Albani B, Albuquerque FC, Alexander MJ, et al: Embolectomy for stroke with emergent large vessel occlusion (ELVO): report of the Standards and Guidelines Committee of the Society of NeuroInterventional Surgery. J Neurointerv Surg 7:316321, 2015 (Erratum in J Neurointerv Surg 7:622, 2015)

37. Kollár J, Schulte-Altedorneburg G, Sikula J, Fülesdi B, Ringelstein EB, Mehta V, et al: Image quality of the temporal bone window examined by transcranial Doppler sonography and correlation with postmortem computed tomography measurements. Cerebrovasc Dis 17:61-65, 2004

38. Kyriakou A, Neufeld E, Werner B, Székely G, Kuster N: Full-wave acoustic and thermal modeling of transcranial ultrasound propagation and investigation of skull-induced aberration correction techniques: a feasibility study. J Ther Ultrasound 3:11, 2015

39. Labib MA, Shah M, Kassam AB, Young R, Zucker L, Maioriello A, et al: The safety and feasibility of image-guided BrainPath-mediated transsulcul hematoma evacuation: a multicenter study. Neurosurgery 80:515-524, 2017

40. Lin KW, Hall TL, McGough RJ, Xu Z, Cain CA: Synthesis of monopolar ultrasound pulses for therapy: the frequencycompounding transducer. IEEE Trans Ultrason Ferroelectr Freq Control 61:1123-1136, 2014

41. Liu HL, Jan CK, Chu PC, Hong JC, Lee PY, Hsu JD, et al: Design and experimental evaluation of a 256-channel dualfrequency ultrasound phased-array system for transcranial blood-brain barrier opening and brain drug delivery. IEEE Trans Biomed Eng 61:1350-1360, 2014

42. Luo H, Steffen W, Cercek B, Arunasalam S, Maurer G, Siegel RJ: Enhancement of thrombolysis by external ultrasound. Am Heart J 125:1564-1569, 1993

43. Lutz H, Buscarini E: Manual of Diagnostic Ultrasound, ed 2. Geneva: World Health Organization, 2011

44. Ma J, Shui S, Han X, Guo D, Li TF, Yan L: Mechanical thrombectomy with Solitaire AB stents for the treatment of intracranial venous sinus thrombosis. Acta Radiol 57:1524_ 1530,2016

45. Maxwell AD, Cain CA, Duryea AP, Yuan L, Gurm HS, Xu Z: Noninvasive thrombolysis using pulsed ultrasound cavitation therapy-histotripsy. Ultrasound Med Biol 35:1982-1994, 2009

46. Maxwell AD, Owens G, Gurm HS, Ives K, Myers DD Jr, Xu $\mathrm{Z}$ : Noninvasive treatment of deep venous thrombosis using pulsed ultrasound cavitation therapy (histotripsy) in a porcine model. J Vasc Interv Radiol 22:369-377, 2011

47. Medel R, Crowley RW, McKisic MS, Dumont AS, Kassell NF: Sonothrombolysis: an emerging modality for the management of stroke. Neurosurgery 65:979-993, 2009

48. Mendelow AD, Gregson BA, Rowan EN, Murray GD, Gholkar A, Mitchell PM: Early surgery versus initial conservative treatment in patients with spontaneous supratentorial lobar intracerebral haematomas (STICH II): a randomised trial. Lancet 382:397-408, 2013

49. Molina CA, Barreto AD, Tsivgoulis G, Sierzenski P, Malkoff MD, Rubiera M, et al: Transcranial ultrasound in clinical sonothrombolysis (TUCSON) trial. Ann Neurol 66:28-38, 2009

50. Monteith SJ, Harnof S, Medel R, Popp B, Wintermark M, Lopes MB, et al: Minimally invasive treatment of intracerebral hemorrhage with magnetic resonance-guided focused ultrasound. J Neurosurg 118:1035-1045, 2013

51. Monteith SJ, Kassell NFN, Goren O, Harnof S: Transcranial MR-guided focused ultrasound sonothrombolysis in the treatment of intracerebral hemorrhage. Neurosurg Focus 34(5):E14, 2013

52. Mould WA, Carhuapoma JR, Muschelli J, Lane K, Morgan TC, McBee NA, et al: Minimally invasive surgery plus recombinant tissue-type plasminogen activator for intracerebral hemorrhage evacuation decreases perihematomal edema. Stroke 44:627-634, 2013

53. Mozaffarian D, Benjamin EJ, Go AS, Arnett DK, Blaha MJ, Cushman M, et al: Executive summary: heart disease and stroke statistics-2015 update. Circulation 131:434-441, 2015

54. Nacu A, Kvistad CE, Naess H, Øygarden H, Logallo N, Assmus J, et al: NOR-SASS (Norwegian Sonothrombolysis in Acute Stroke Study): randomized controlled contrastenhanced sonothrombolysis in an unselected acute ischemic stroke population. Stroke 48:335-341, 2017

55. Nedelmann M, Eicke BM, Lierke EG, Heimann A, Kempski O, Hopf HC: Low-frequency ultrasound induces nonenzymatic thrombolysis in vitro. J Ultrasound Med 21:649-656, 2002

56. Nolte CH, Doepp F, Schreiber SJ, Gerischer LM, Audebert HJ: Quantification of target population for ultrasound enhanced thrombolysis in acute ischemic stroke. $\mathbf{J}$ Neuroimaging 23:79-81, 2013

57. Pajek D, Burgess A, Huang Y, Hynynen K: Highintensity focused ultrasound sonothrombolysis: the use of perfluorocarbon droplets to achieve clot lysis at reduced acoustic power. Ultrasound Med Biol 40:2151-2161, 2014

58. Pajek D, Hynynen K: The design of a focused ultrasound transducer array for the treatment of stroke: a simulation study. Phys Med Biol 57:4951-4968, 2012

59. Phenix CP, Togtema M, Pichardo S, Zehbe I, Curiel L: 
High intensity focused ultrasound technology, its scope and applications in therapy and drug delivery. J Pharm Pharm Sci 17:136-153, 2014

60. Powers WJ, Derdeyn CP, Biller J, Coffey CS, Hoh BL, Jauch EC, et al: 2015 American Heart Association/American Stroke Association focused update of the 2013 guidelines for the early management of patients with acute ischemic stroke regarding endovascular treatment: a guideline for healthcare professionals from the American Heart Association/ American Stroke Association. Stroke 46:3020-3035, 2015

61. Przybylowski CJ, Ding D, Starke RM, Webster Crowley R, Liu KC: Endoport-assisted surgery for the management of spontaneous intracerebral hemorrhage. J Clin Neurosci 22:1727-1732, 2015

62. Rosenschein U, Furman V, Kerner E, Fabian I, Bernheim J, Eshel Y: Ultrasound imaging-guided noninvasive ultrasound thrombolysis: preclinical results. Circulation 102:238-245, 2000

63. Saqqur M, Tsivgoulis G, Nicoli F, Skoloudik D, Sharma VK, Larrue $\mathrm{V}$, et al: The role of sonolysis and sonothrombolysis in acute ischemic stroke: a systematic review and meta-analysis of randomized controlled trials and case-control studies. J Neuroimaging 24:209-220, 2014

64. Schwamm LH, Ali SF, Reeves MJ, Smith EE, Saver JL, Messe S, et al: Temporal trends in patient characteristics and treatment with intravenous thrombolysis among acute ischemic stroke patients at Get With The Guidelines-Stroke hospitals. Circ Cardiovasc Qual Outcomes 6:543-549, 2013

65. Shui SF, Li TF, Han XW, Ma J, Guo D: Balloon dilatation and thrombus extraction for the treatment of cerebral venous sinus thrombosis. Neurol India 62:371-375, 2014

66. Sokka SD, Gauthier TP, Hynynen K: Theoretical and experimental validation of a dual-frequency excitation method for spatial control of cavitation. Phys Med Biol 50:2167-2179, 2005

67. Song J, Pulkkinen A, Huang Y, Hynynen K: Investigation of standing-wave formation in a human skull for a clinical prototype of a large-aperture, transcranial MRguided focused ultrasound (MRgFUS) phased array: an experimental and simulation study. IEEE Trans Biomed Eng 59:435-444, 2012

68. Suo D, Guo S, Lin W, Jiang X, Jing Y: Thrombolysis using multi-frequency high intensity focused ultrasound at $\mathrm{MHz}$ range: an in vitro study. Phys Med Biol 60:7403-7418, 2015

69. Tsivgoulis G, Eggers J, Ribo M, Perren F, Saqqur M,
Rubiera M, et al: Safety and efficacy of ultrasound-enhanced thrombolysis: a comprehensive review and meta-analysis of randomized and nonrandomized studies. Stroke 41:280-287, 2010

70. Tsivgoulis G, Safouris A, Katsanos AH, Arthur AS, Alexandrov AV: Mechanical thrombectomy for emergent large vessel occlusion: a critical appraisal of recent randomized controlled clinical trials. Brain Behav 6:e00418, 2016

71. Weiss HL, Selvaraj P, Okita K, Matsumoto Y, Voie A, Hoelscher T, et al: Mechanical clot damage from cavitation during sonothrombolysis. J Acoust Soc Am 133:3159-3175, 2013

72. Westermark S, Wiksell H, Elmqvist H, Hultenby K, Berglund $\mathrm{H}$ : Effect of externally applied focused acoustic energy on clot disruption in vitro. Clin Sci (Lond) 97:67-71, 1999

73. Wright C, Hynynen K, Goertz D: In vitro and in vivo highintensity focused ultrasound thrombolysis. Invest Radiol 47:217-225, 2012

74. Yaghi S, Boehme AK, Dibu J, Leon Guerrero CR, Ali $\mathrm{S}$, Martin-Schild S, et al: Treatment and outcome of thrombolysis-related hemorrhage: a multicenter retrospective study. JAMA Neurol 72:1451-1457, 2015

75. Yang W, Zhou Y: Effect of pulse repetition frequency of high-intensity focused ultrasound on in vitro thrombolysis. Ultrason Sonochem 35 (Pt A):152-160, 2017

\section{Disclosures}

The authors report no conflict of interest concerning the materials or methods used in this study or the findings specified in this paper.

\section{Author Contributions}

Conception and design: Ilyas, Chen. Acquisition of data: Ilyas. Analysis and interpretation of data: Ilyas, Chen. Drafting the article: Ilyas. Critically revising the article: all authors. Reviewed submitted version of manuscript: all authors. Approved the final version of the manuscript on behalf of all authors: Ilyas. Administrative/technical/material support: Kalani, Park. Study supervision: Kalani, Park.

\section{Correspondence}

Adeel Ilyas: University of Alabama at Birmingham, AL. adeelilyas@uabmc.edu. 